\title{
OTIMIZAÇÃO DA UTILIZAÇÃO DE MEDICAMENTOS NAS UNIDADES BÁSICAS DE SAÚDE COM FOCO NOS PACIENTES POLIFARMÁCIA
}

\author{
Nanci Vaquero \\ nanci.vaquero@einstein.br \\ Hospital Israelita Albert Einstein
}

\section{INTRODUÇÃO}

Tem sido observado excesso de medicamentos nas casas dos pacientes, o que reforça a suspeita de tratamento farmacológico inadequado e desperdício, até então sem monitoramento. Além disso, a farmácia recebe mensalmente um alto número de descarte de medicamentos pela população, vencidos ou sem uso. Em 2017, na UBS Jd. das Palmas foram descartados $77,6 \mathrm{~kg}$ de medicamentos, 0 que equivale a um custo próximo a $\mathrm{R} \$ 54.320$. Considerando uma projeção deste cenário para as 13 UBS do parceiro, o desperdício estimado é de cerca de $\mathrm{R} \$ 706.160 / a n o$. A polifarmácia (uso de 5 ou mais fármacos por um paciente) é frequentemente associada a desfechos negativos para o paciente, aumento de morbidades, redução da qualidade de vida, especialmente em idosos e aumento dos custos para o cuidado, com impacto para pacientes e sistema de saúde.
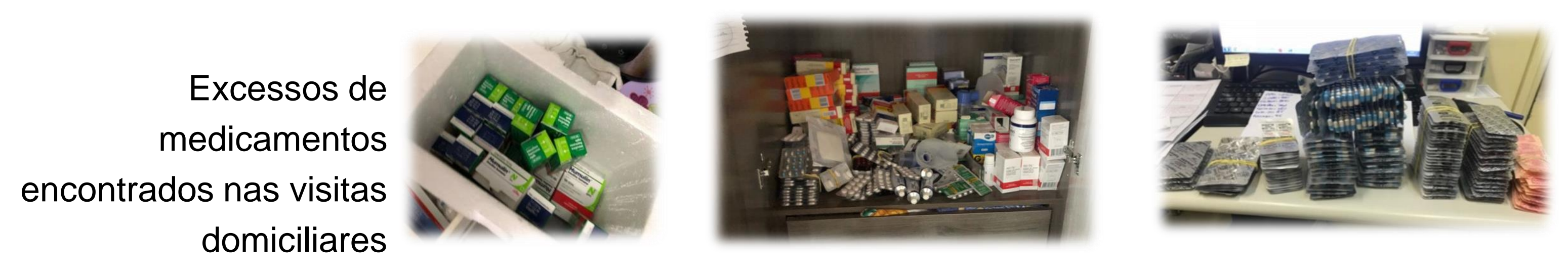

\section{OBJETIVO}

Relatar a experiência da assistência farmacêutica nas vistas domiciliares (VDs) a fim de reduzir o desperdício de medicamentos e ampliar a segurança do paciente polifarmácia.

\section{MÉTODO}

Para o desenvolvimento do projeto foi utilizada a metodologia Lean Six Sigma e levantadas as causas que levam ao descarte de medicamentos. Para a coleta de dados foram pesados os medicamentos devolvidos e realizadas 331 VDs e foram verificadas condições de armazenamento, adesão ao tratamento, reações adversas e feitas intervenções para segurança do tratamento.

\section{RESULTADOS}

Após a coleta dos dados por 7 meses em 2018, constatou-se que 9 UBS representaram cerca de $82 \%$ da quantia total de descarte de medicamentos, o que refere-se a um desperdício de $677,13 \mathrm{~kg}$ ( $R$ \$473.991). Com os dados das visitas, notou-se que $72 \%$ dos pacientes têm idade acima de 60 anos. Estudos reforçam que a polifarmácia é comum e crescente, principalmente em idosos. E apenas $5 \%$ dos pacientes têm o segundo ou terceiro grau de escolaridade, $59 \%$ esquecem de tomar os medicamentos e, consequentemente, possuem excessos. $O$ projeto tem gerado ações como o fracionamento de antibióticos, que visa à efetividade do tratamento e a redução de desperdício.
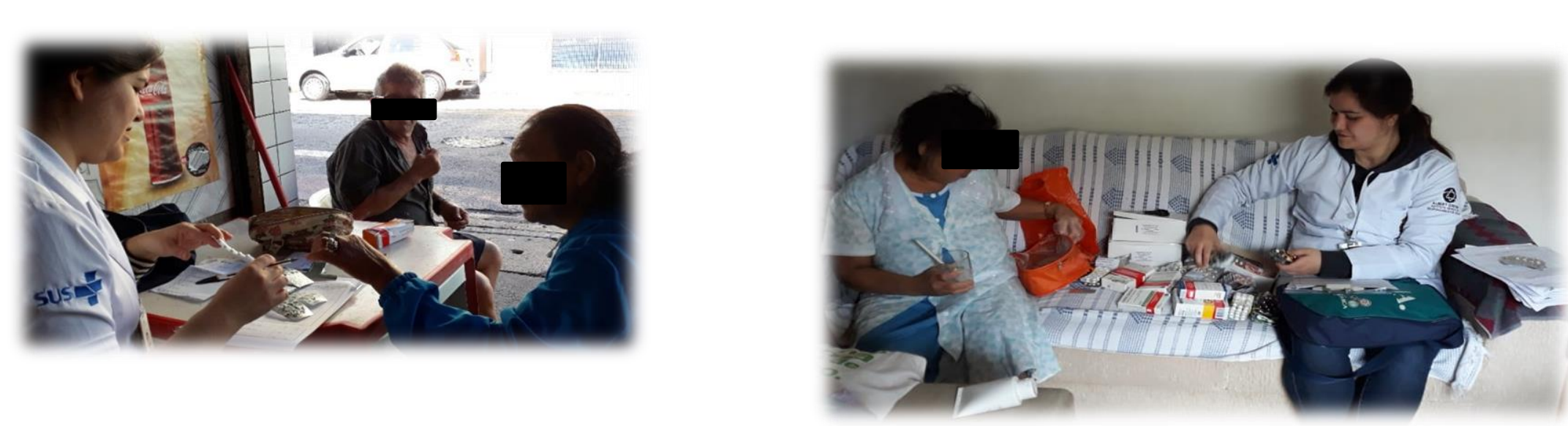

Farmacêutico em atendimento nas visitas domiciliares

\section{Perfil dos Pacientes Polifarmácia}

$n=331 ;$ nível de confiança $=95 \% ;$ erro amostral $=5,2 \%$
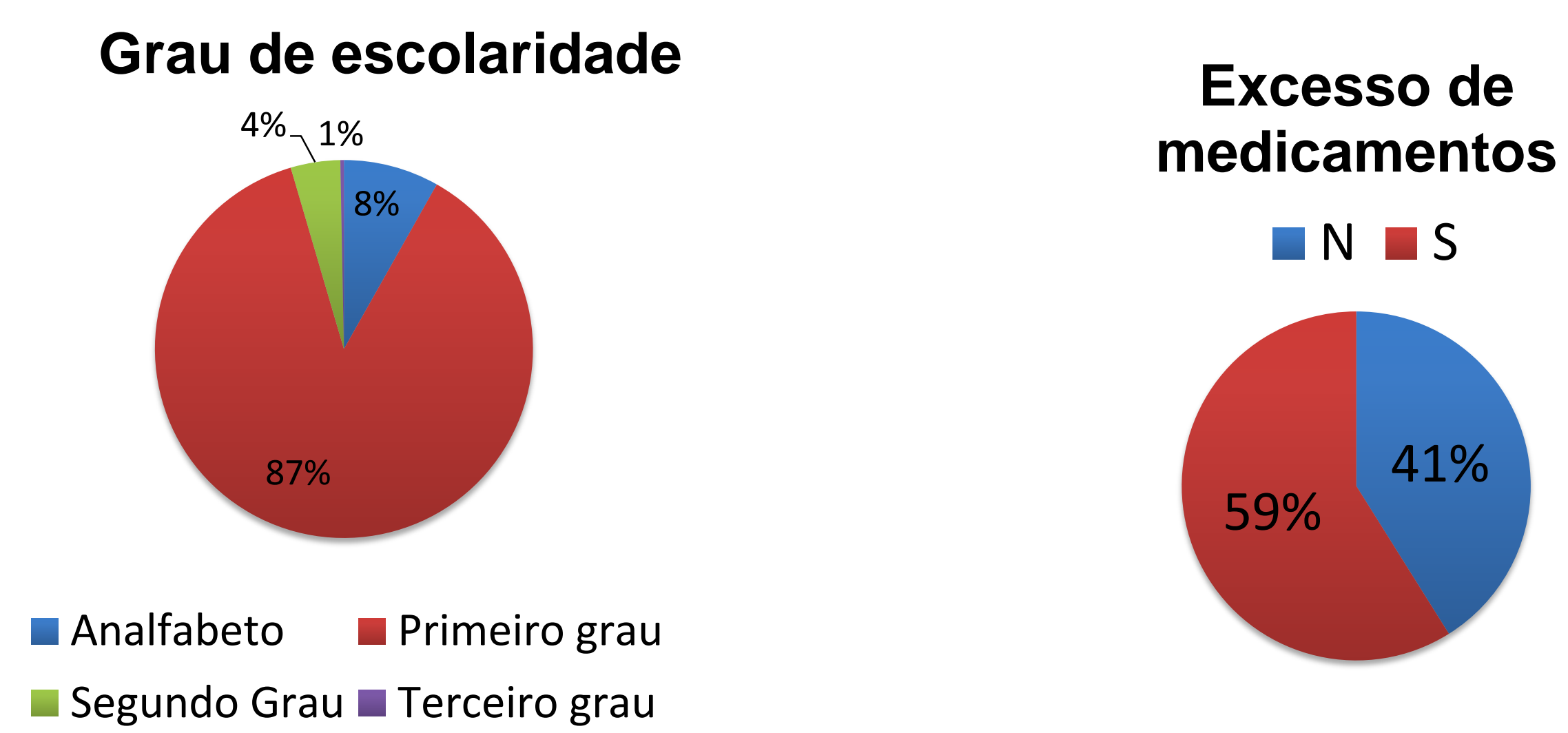

Esquece de tomar medicamento

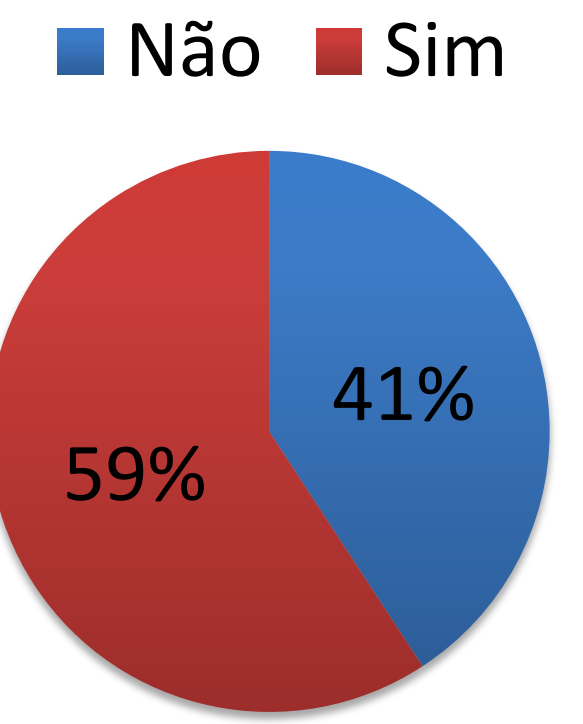

\section{CONSIDERAÇÕES FINAIS}

A assistência farmacêutica tem como finalidade contribuir na melhoria, prevenção, reabilitação da saúde e redução de desperdício de medicamentos. Por isso, a presença do farmacêutico está sendo um diferencial nas discussões dos casos e terapêutica, melhorando a adesão dos pacientes.

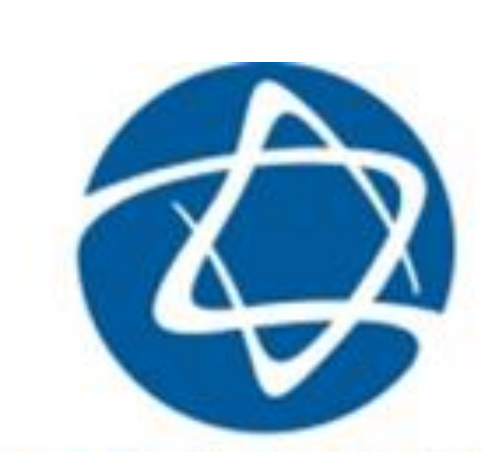

ALBERT EINSTEIN

SOCIEDADE BENEFICENTE ISRAELITA BRASILEIRA hospital • ensino e PESQUisa - Responsabilidade social

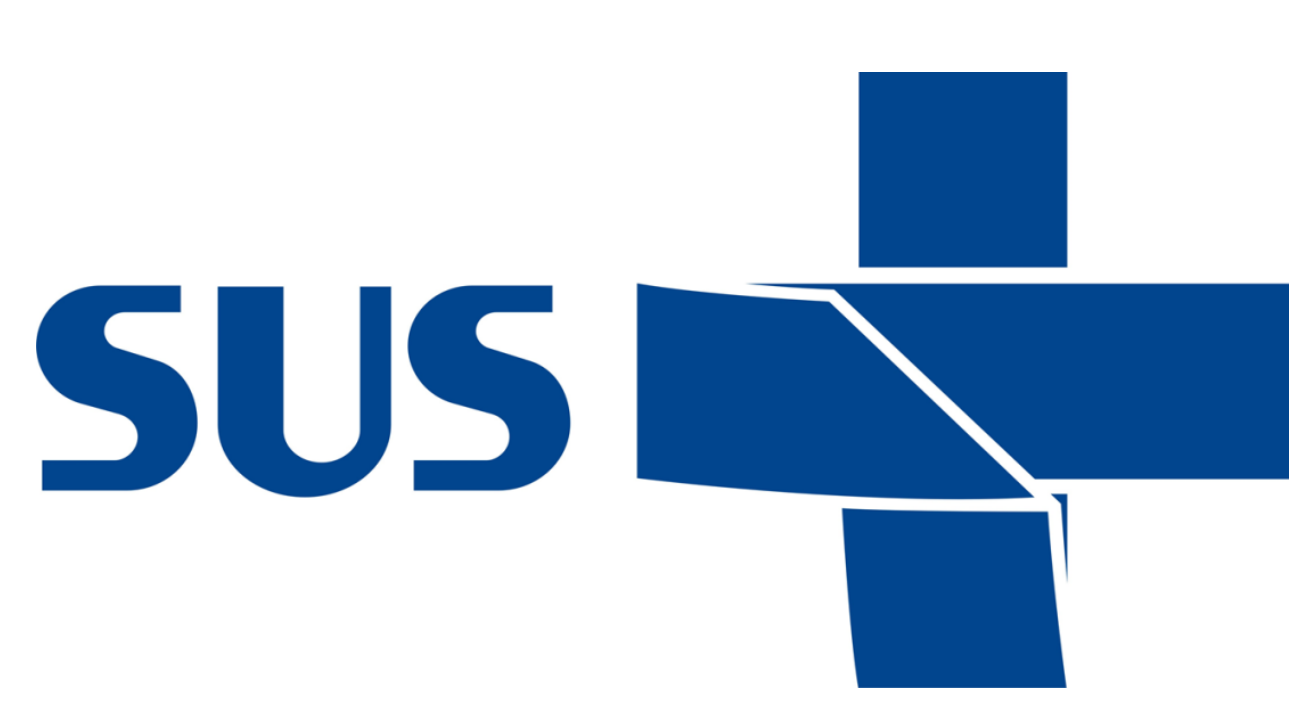

\section{PREFEITURA DE SÃO PAULO}

SAÚDE 